\title{
Subconjunctival Orbital Fat Prolapse: Case Report
}

Bouchra Tamym*, Bouchra. Tarik Bouzouba, Imane Chabbar, Amina Berraho

Ophtalmologie B, Hôpital des Spécialités de Rabat, Morocco

DOI: $10.36347 /$ sjmcr.2020.v08i06.010

| Received: 20.01.2020 | Accepted: 27.01.2020 | Published: 18.06.2020

*Corresponding author: Bouchra Tamym

\section{Abstract}

\section{Case Report}

Subconjunctival orbital fat prolapse is a rare and unsuspected benign entity. We report a case of a subconjunctival fat prolapse in a 89 years old patient.

Keywords: Subconjunctival Orbital, Fat Prolapse, acquired.

Copyright @ 2020: This is an open-access article distributed under the terms of the Creative Commons Attribution license which permits unrestricted use, distribution, and reproduction in any medium for non-commercial use (NonCommercial, or CC-BY-NC) provided the original author and source are credited.

\section{INTRODUCTION}

The subconjunctival fat prolapse is the herniation of the intraconal orbital fat, generally bilateral, acquired; resulting from weakness of the eyeball due to aging, trauma or surgery [1]. Clinically manifested by a yellowish mass in the lateral corner of the eye, which becomes more evident with the retropulsion of the globe [2].

\section{Clinical Case}

An 89-year-old woman presented with an asymptomatic yellowish mass on her temporal bulbar conjunctiva of the left eye.

The ocular examination finds visual acuity with movement of the fingers related to a corticonuclear cataract, a soft, yellowish and painless mobile mass (figure 1). It is a hernia of the orbital fat under the conjunctiva, also known under the name of intraconal fat prolapse. The rest of the exam is unremarkable.
The patient underwent transconjunctival excision, with no signs of recurrence.

\section{DISCUSSION}

Subconjunctival fat prolapse is rare, of relatively easy clinical diagnosis [3]; as a yellowish fat epibulbar mass in the lateral corner of the orbit, with thin blood vessels, which is easily repositioned in the orbit with a tipped applicator; more visible at the retropulsion of the globe [4]. Can be confused with dermolipoma [5].

Treatment consists of transconjunctival excision, a simple, safe and effective surgical technique; with a recurrence rate after excision of around $9 \%[6]$.

\section{Concluusion}

Subconjunctival orbital fat prolapse is a rare clinical entity in which intraconal orbital fat herniated in the subconjunctival space. Its diagnosis is mainly clinical.

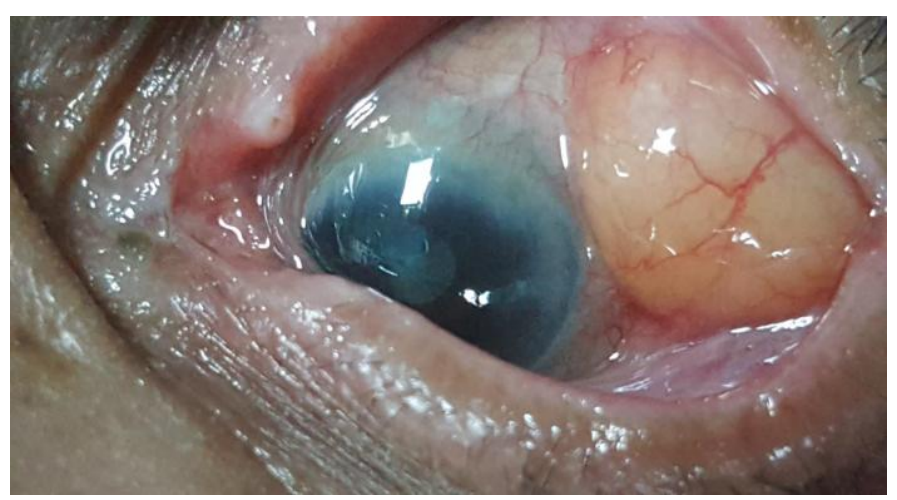

Fig-1: Subconjunctival orbital fat hernia 


\section{REFERENCES}

1. Kim E, Kim HJ, Kim YD. Subconjunctival fat prolapse and dermolipoma of the orbit: differentiation on CT and MR imaging. AJNR Am J Neuroradiol. 2011; 32:465-7.

2. Schmack I, Patel RM, Folpe AL. Subconjunctival Herniated orbital fat: A benign adipocytic lesion that may mimic pleomorphic lipoma and atypical lipomatous tumor. Am J Surg Pathol. 2007; 31:193-8.
3. Wang X, Yan J. Subconjunctival orbital fat prolapse: an unsuspecting rare lesion. J Craniofac Surg, 2015; 26:e92-4.

4. Jordan DR, Tse DT. Herniated orbital fat. Can J Ophthalmol, 1987; 22:173-177.

5. Otaka I, Kyu N. A new surgical technique for management of conjunctivochalasis. $A m J$ Ophthalmol. 2000; 129:385-387.

6. McNab AA, Wright JE, Caswell AG. Clinical features and surgical management of dermolipomas. Aust N Z J Ophthalmol. 1990; 18:159-62. 